\title{
Discussion on the Change of Nationalism in German Gymnastics in the 19th Century: Focusing on Two Nationalists
}

\author{
Dong-Soo Jeong and Bang-Chool Kim*
}

Seoul National University of Education

\author{
Article Info \\ Received 2021.11.01. \\ Revised 2021.12.10. \\ Accepted 2021.12.10. \\ Correspondence* \\ Bang-Chool Kim \\ kim507@snue.ac.kr
}

\section{Key Words}

German gymnastics,

Nationalsim,

Nationalists,

Fridrich jahn,

Adolf spiess

이 논문은 2021년도 서울교육대학교

교내연구비의 지원을 받아 수행된 연구임.
PURPOSE This study examined the process and cause of change in nationalism in German gymnastics in the 19th century. METHODS The study used a literature study method and analyzed data from previous studies. Eleven articles related to the research topic were chosen for domestic research data by searching RISS for "German gymnastics," "Turnen," and "German nationalism." Overseas research data involved seven articles related to this study and were found by searching for "German gymnastics" and "Turnen" in Google Scholar. RESULTS First, German nationalism was originally divided into liberal nationalism and nationalistic nationalism, resulting in nationalistic nationalism after German reunification. Second, Jahn as a liberal nationalist and Spiess as a nationalist attempted to spread their ideas through German gymnastics. Finally, German gymnastics change from Jahn's liberal nationalism to Spiess' nationalistic nationalism was inevitable due to German gymnastics' external background and inherent limitations. CONCLUSIONS This study illustrated the process and cause of the change in the nationalistic characteristics of German gymnastics in the 19th century. Various historical cases that have not yet received attention but are worthy of investigation must be studied.

\section{서론}

본 연구는 독일체조에 관한 연구에서 크게 관심을 갖지 않았던 부분 을 짚고자 하는 하나의 '정보'이다. 이 정보는 기존의 연구에서 언급하 지 않았거나 언급하였더라도 가볍게 넘어가곤 했던, 19세기 독일체조 의 성격 변화에 대한 부분이다.

기존의 연구들은 독일체조가 19 세기를 거치며 결과적으로 갖게 되 는 국가주의적인 성격에 중점을 두어 바라보고 서술한다. 실제로 19 세기 말 군국주의적인 성격을 강하게 띠는 프로이센에 의한 독일의 통일은, 독일체조가 국가주의적인 모습을 띠는 데 큰 역할을 하였다 (Reicher, 2020). 하지만 기존의 연구들 대부분이 독일의 통일 과정 에서 체조가 어떠한 역할을 하였는지, 혹은 그러한 상황에서는 어떠 한 성격을 가지고 있었는지의 여부에 주목하지 않았다. 단지 독일체 조가 결과적으로 갖게 된 성격과 사상에 초점을 맞추고 있거나, 그 것을 연구의 전제로 삼고 있다(Oh, 1989; 2006, Park, 2017; Kim, 2009; Nam, Soh \& Kim, 2017).

(cc) This is an open-access article distributed under the terms of the Creative Commons Attribution Non-Commercial License (http://creativecommons.org/ licenses/by-nc/4.0/), which permits unrestricted non-commercial use, distribution, and reproduction in any medium, provided the original work is properly cited.
하지만 필자들은 19 세기를 관통하는 독일체조가 갖는 민족주의적 인 성격의 변화에 주목해볼 필요가 있다고 판단하였다. 체조는 당시 독일 민족주의의 성격을 보여주는 가장 대표적인 신체문화였다. 그 렇기에 초기에 자유롭고 진보적이었던 독일체조가 통일된 독일 내에 서 비주류의 문화로 전락하는 과정은 독일 사회의 자유주의적 민족주 의가 소멸되는 과정을 대리하여 보여주는 것으로 판단하였다. 따라서 독일체조는 독일의 당대 사회 분위기를 반영하는 일종의 재현이 이루 어지는 매개로서 역할을 수행하고 있는 것으로 보았다.

다소 거친 비교이겠지만, $\operatorname{Kim}(2009)$ 의 연구에서도 당시 독일 사회 의 사회 경제적인 변화와 더불어 여성의 교육 기회 및 사회참여가 확 대되던 시대적인 조류에 발맞추어 여성 체조가 확대되었음을 밝히고 있다. 즉 독일 사회의 변화상을 독일의 여성체조가 재현하고 있는 것 으로 판단할 수 있다.

필자들은 이를 위해 독일체조를 '민족주의'적인 관점에서 바라보았 다. 이러한 관점으로 독일체조를 바라보면서 필자들이 제공하고자 하 는 '정보'의 핵심을 요약하자면 다음과 같다. 19세기 초 독일체조는 '프 리드리히 얀(Fridrich Ludwig Jahn)'이 지녔던 '자유주의적 민족주의' 의 성격이 강한 신체문화였으나, 19 세기 중반 이후에 접어들면서 '아 돌프 스피스(Adolf Spiess)'가 추구하는 '국가주의적 민족주의'의 성격 으로 변화하게 되었다는 점이다. 하지만 이 연구에서 말하고자 하는 바 
는, 단지 독일체조의 성격이 변하였다는 사실 그 자체에 있지는 않다.

독일체조의 민족주의적인 성격이 변화되는 데 가장 큰 영향력을 끼 친 것은 독일 사회의 변화였다. 구체적으로 서술하면, 사상적으로 진 보적인 색채를 띠었던 독일 사회가 점차 국가주의적이고 보수적인 사 회로 굳어진 것이 독일체조의 변화를 이끌었다고 볼 수 있다. 독일 사 회의 변화는 당시 독일체조를 이끌었던 여러 지도자에게 영향을 주었 고, 이는 독일체조에도 변화가 전이되는 결과를 가져왔다. 그로 인해 독일체조에서도 독일 사회의 모습이 재현된다(Krüger, 1996).

이러한 필자들의 주장을 구체화하기 위해, II장에서는 독일의 민족 주의가 발아하던 시기 유럽의 상황을 간략하게 짚을 것이다. 그리고 이와 함께 민족주의의 분화가 나타나고 있음을 서술할 것이다. 이러 한 분화의 핵심은 국가(nation)의 기준이 되기 위한 민족(folk)공동체 와 국가(state)공동체와의 경쟁에 있다(Kang, 2001). 그리고 이 경쟁 의 결과는 독일의 통일이 이루어지면서 결정되게 되는데, 이 과정을 민족, 국가 등의 개념과 함께 서술하고자 한다.

III장에서는 민족주의자이자 체조인이었던 얀과 스피스 시대의 체 조를 개괄하고, 당시 체조가 지녔던 특징적인 요소들에 대해 서술할 것이다. 얀의 체조와 스피스의 체조를 개괄하는 연구는 기존에 이루 어져 있기에(Oh, 1989; 2006), 민족주의적으로 볼 수 있는 요소에 집 중하여 서술하고자 한다.

이러한 서술의 과정에서 얀과 스피스로 대표되던 19세기 초기의 체 조가 지녔던 모습과 중반 이후의 모습 중 일부를 발췌하여 드러내고 자 한다. 이러한 발췌를 통해 독일체조가 지녔던 민족주의적인 성격 의 변화가 이루어지는 과정을 파악할 것이다.

첨언하자면 III장의 두 번째 절인 스피스에 관한 부분은 관련 연구가 많지 않은 관계로 Oh(1989)와 Kwak(2008)의 연구를 주된 자료로써 인용할 것이다. 또한 Kant(2016)와 Tröhler(2017)의 연구에서 적은 비중으로 서술되는 스피스의 생애 및 그의 체조의 특성을 토대로 연 구한 결과임을 미리 밝힌다.

이렇게 독일체조의 성격이 변화하는 과정을 알아본 이후, IV장에서 는 독일체조가 변화할 수밖에 없었던 당대의 맥락에 대해 짚어볼 것이 다. 이 분석은 민족 및 민족주의적 관점을 바탕으로 이루어질 것이다.

구체적으로 19세기 유럽에서 민족주의가 탄생하는 과정 중 독일 사 회가 겪었던 상황은 영국이나 미국, 프랑스가 경험한 것과는 차이가 있다. 거칠게 나누자면 앞서 언급한 국가들은 상대적으로 '자유주의 적인 민족주의'를 발전시켜 왔다. 하지만 독일에는 '국가주의적인 민 족주의'가 사회 전반에 녹아있었다. 이러한 성격은 독일이 극단적인 파시즘으로 이어지는 흐름의 초기형태로 볼 수 있을 경직된 형태로 나타났다(Hong, 2019).

이러한 역사적인 사실에 근거하여 독일 사회가 변화하였던 방향과 당시 독일의 대응을 근거로 독일 사회의 분위기를 파악할 것이다. 위 와 같은 시각으로 독일체조를 바라보면서 독일체조가 변화한 이유, 정확히는 변화할 수밖에 없었던 이유에 대해 파악해보고자 한다. 마 지막으로 $\mathrm{V}$ 장에서는 이번 연구의 전반적인 결과에 대한 요약과 연구 의 가치, 그리고 간단한 소회를 담으며 글을 마무리하고자 한다.

\section{독일 내 민족주의의 분화와 독일 통일 이후의 결과}

19세기 초반까지 독일이라는 명칭은 사실상 지리적인 표현이었다. 이 들은 수십 개의 연방국가로 갈라져 있었을 뿐 아니라, 그들을 공동체
로서 묶어주는 것은 신성로마제국이라는 헐거운 형태였기 때문이다. 당시 신성로마제국은 여러 민족을 포괄하는 거대하지만 느슨한 형태 로 존재하고 있었고, 따라서 독일은 근본적으로 민족이나 국가적 정 체성이 희미할 수밖에 없다. 요컨대 독일은 근대적인 민족국가와는 꽤나 다른 형태로 존재하고 있었다는 것이다(Brueilly, 1992).

독일이 민족국가로서 발돋움을 하도록 이끌었던 것은 아이러니하 게도 독일을 침공하였던 나폴레옹이었다. 프랑스혁명의 여파는 전 유 럽으로 퍼져나갔고, 당연히도 프랑스의 옆 나라인 독일에까지 영향을 주었다. 당시 독일은 나폴레옹에 의해 신성로마제국이 해체되며, 공 동체적인 위협을 경험하게 된다. 이러한 과정은 독일인들이 '민족'의 개념에 대해 인식할 수 있도록 돕는 역할을 하였다(Kang, 2001).

그러나 앞서 서술한 것처럼 독일은 수십 개의 국가로 나누어져 있 었다. 그렇기에 독일인들은 새롭게 인식하게 된 '민족(folk)' 의 개념을 토대로 하는 공동체를 형성하고자 했다. 이 과정에서 독일인들은 그 들 내의 공통적인 요소를 찾아야 했고, 당시 독일 내 공통적인 요소로 인정될 만한 것은 전통이나 문화 외에는 없었다. 따라서 점차 독일은 문화를 기초로 하는 '민족'의 개념을 형성하게 된다(Kang, 2001).

이 부분에서 짚고 넘어가야 할 부분은 위에서 서술한 '문화'를 기준 으로 하는 '민족(folk)'의 개념을 Lepsius와 Campbell(2004)의 연구 에서는 앞서 제시한 단어인 folk로 표현하지 않는다. 이는 그들의 연구 에서 folk nation과 cultural nation을 구분하고 있기 때문이다. 즉 민 속(folk)적인 개념을 문화(cultural)적인 것과 구분하고 있다는 것이다.

하지만 필자들의 연구에서는 folk와 cultural이 구분되지 않는다. 이 러한 이유는 독일체조가 'folk'와 'cultural'이 융합된 개념으로 표현되 고 있기 때문이다(Pfister, 2003). 따라서 이번 연구에서는 민족(folk) 내에 문화적인 요소를 포함하는 것으로 전제하고 서술하고자 한다.

당시 독일의 민족공동체는 기존에 독일인들이 공유하던 문화를 근 거로 하는 '민족(folk)'의 개념을 통해 성장하고자 하였다. 물론 이 과 정에서 문화 외에도 언어나 종교, 전통적인 관습 등도 민족을 형성하 는 근거가 될 수도 있었다.

하지만 독일의 민족 개념은 프랑스의 침공으로 인한 공동체적 위기 에서 촉발한 것이기에 프랑스와 공유할 수 있는 언어, 종교, 관습 등은 민족을 가르는 기준에서 배제될 수밖에 없었다. 따라서 독일민족은 독일 문화를 공유하는 집단으로 서서히 받아들여지게 된다(Seehan, 1993).

따라서 독일의 민족주의는 문화를 기본 근거로 하여 민족주의를 전 개하게 된다. 하지만 문화라는 기준은 꽤나 주관적으로 받아들여질 수밖에 없었다. 이는 명확한 기준이 없다는 말과 같았고, 그렇기에 독 일의 민족공동체가 주도하는 민족주의 운동은 쉽지 않은 과정이었다. 특히나 민족주의의 목표는 민족공동체 내부의 단일성이나 민족 간 연 대감과 동질감의 형성이라는 의식적인 차원에 존재하였기에, 더욱 달 성하기 어려운 측면이 있었다(Hong, 2019).

게다가 문화에 의한 민족적 개념은 일정 수준 이상의 지식과 교양 을 겸비한 계층에게만 이해되는 일종의 상상의 공동체였다(Seehan, 1993). 그렇기에 당시 독일의 모든 계층이 민족의 개념을 토대로 통 일된 독일을 염원하고 있었던 것도 아니었다. 따라서 통일된 독일을 이루는 과정은 난해한 과정이 될 수밖에 없었다.

한편 민족공동체와는 달리 법과 제도라는 객관적인 기준을 가질 수 있었던 국가(state)공동체는 상대적으로 쉽게 독일인들의 마음속에 자 리 잡을 수 있는 측면이 있었다. 쉬운 예로 국가공동체는 독일의 개별 정부를 떠올릴 수 있을 것이다. 
하지만 국가공동체 역시 수십여 개의 국가로 분리되어있는 독일의 현실적인 상황에 의해 많은 이들에게 받아들여지기는 어려웠다. 그렇 기에 국가공동체가 주도하는 민족주의 역시 빛을 발할 수는 없었다. 이 과정에서 19 세기 독일에서의 민족공동체는 국가공동체의 개념과 충돌하면서 상호 간의 긴장 관계를 만들어 내게 된다(Kang, 2001).

이러한 민족공동체와 국가공동체의 개념이 대결하는 과정은 독일체 조의 민족주의적 성격을 가르는 연장선으로 이해할 수 있다. 물론 민 족주의는 용어 및 민족을 규정하는 기준, 민족주의 등이 학문적으로 다양하게 얽혀있다(Kim, 2002). 그렇기에 필자들의 주장 역시 여러 가지 학문적인 견해 중 하나일 것이라는 전제를 바탕으로, 독일의 민 족공동체와 국가공동체가 주도한 민족주의 운동을 구분하고자 한다.

짐작하건대 '민족(folk)'공동체의 민족주의 운동은 영국이나 미국, 프랑스 등에서 이루어졌던 '자유주의적 민족주의'와 비슷한 결을 가 지고 있는 것으로 보인다. 이것은 시민들이 민주주의의 주체로 등장 하면서 개인과 시민이 성장하고, 이를 통해 국가의 건설과 발전이 이 루어질 수 있었던 형태이다. 이러한 형태는 국민국가로 일찍이 변모 하였던 국가들에 해당한다(Hong, 2019).

이와는 달리 '국가(state)' 공동체가 이끄는 민족주의 운동은 독일, 이 탈리아, 러시아 등에서 나타나는 '국가주의적 민족주의'의 형태와 유 사하다. 이는 상대적으로 국민국가의 건설이 늦게 이루어진 국가들에 서 나타난다. 이러한 국가들에서는 국민국가의 형성이 늦은 만큼 시민 들에 의한 민주주의의 성숙을 기다리기보다는, 국가나 정부가 주도한 국가주의적인 움직임이 나타나게 된다.

독일의 민족주의의 성격은 통일 이전에는 '민족'공동체와 '국가' 공 동체의 민족주의가 혼재되어 나타난다. 그러나 프로이센에 의해 통 일이 된 이후부터는 점차 '국가'공동체의 민족주의가 주된 것으로 자 리 잡는다(Kim, 2002). 이는 '국가(state)' 공동체의 기준이었던 법과 제도가 독일의 통일 이후에 모든 독일인들에게 똑같이 적용되는 것이 가능해졌기 때문이다. 이들 통해 독일인들은 문화라는 모호한 기준에 의한 '민족'공동체의 민족주의보다는, 법률이나 제도에 의거하는 '국 가'공동체의 민족주의를 더 쉽게 받아들이게 되었다.

이는 통일 이후의 독일 내의 민족주의가 '국가' 공동체에 의한 민족 주의로 귀결될 수밖에 없음을 의미하는 것이다.

\section{민족주의적 관점을 중심으로 본 얀과 스피스의 체조}

이번 장은 19세기 독일 체조사를 대표하는 인물인 프리드리히 얀 (Fridrich Ludwig Jahn)과 아돌프 스피스(Adolf Spiess)를 중심으로 간략하게 그들의 체조를 개괄하는 서술을 하고자 한다. 위의 인물들 은 '독일체조의 아버지', '학교체육의 아버지' 등의 이명을 지닌 19세 기 독일체조를 대표하는 중심적인 인물로 판단되기에 선정하였다.

이번 장에서 분명히 해야 할 지점은 개념 중 하나는 '국가(nation)' 이다. 이는 필자들이 위에서 지속적으로 언급하였던 '국가(state)'와는 개념적으로 다르다. 앞선 장에서 민족(folk)공동체는 문화적인 요소 를 통해 민족을 상정하였다. 그리고 국가(state)공동체는 법과 제도 등 에 의거하는 개별 정부로 거칠게 표현하였다. 이것들과 비교한 국가 (nation)은 민족(folk)과 국가(state)를 포괄하는 개념으로 보는 것이 타당하다.

이는 단순히 두 단어를 합치는 더하기의 개념이라기보다는 '민족 (folk)'과 '국가(state)' 공동체가 '국가(nation)'를 규정하는 기준이 되
고자 경쟁하였고, 독일이 통일된 이후에는 국가(state)공동체가 경 쟁에서 승리한 것으로 이해하고 있다. 이는 민족(folk)공동체와 국가 (state)공동체 모두 민족주의(nationalism) 운동을 통해 강한 국가 (nation)을 만들고자 하였다는 점에 주목한다면 일견 타당한 부분이 있을 것으로 본다.

요컨대 얀과 스피스 모두 독일이 강력한 국가(nation)가 되기를 바 랐다. 하지만 얀의 체조는 '민족(folk)' 공동체적인 이상을 지녔으나, 스피스는 '국가(state)'공동체적 목적을 실현하고자 하였다는 것으로 구분해볼 수 있다. 그리고 이러한 구분은 II장에서 거칠게 연결했던 ‘자유주의적 민족주의'와 ‘국가주의적 민족주의'로 귀결된다.

따라서 아래의 내용에서 필자들이 강조하고자 하는 점은 초기 얀 의 독일체조가 자유주의적 민족주의의 성격을 지닌 신체문화로 시작 되었고, 이후 스피스의 체조는 국가주의적 민족주의적인 성격을 띠게 되었다는 점에 있다.

\section{‘자유주의적 민족주의' 의 관점에서 본 얀의 체조}

이번 절에서 서술할 얀의 체조에 대해 필자가 가장 중요하게 바라보 는 점은 얀의 체조가 자유주의적 민족주의로서의 성격을 띠고 있다는 것이다. 그렇기에 얀의 체조 전체를 개괄하기 보다는 간략하게 서술 하면서 자유주의적 민족주의의 성격을 띠는 요소들에 대해 집중하고 자 한다.

얀의 체조가 무엇인지 축약하여 설명할 때, 독일어 volk, volkstum, volkserziehung를 이해할 필요가 있다. 이 단어는 '사람들', '민족적 문화유산', '대중교육'을 의미한다. 즉 얀은 투르넨이라는 이른바 대중 교육이라는 수단을 통해, 독일민족이 공유하고 있는 문화를 바탕으로 민족의식을 고취하고자 하였다. 이 과정을 통해 당시 연방국가로 흩 어져있던 독일 민족이 강력한 통일국가로 나아가기를 염원하고 있었 다(Pfister, 2003).

물론 얀의 민족주의는 이른바 자유주의적인 민족주의에 바탕 을 두고 있다. 얀은 1811 년 베를린 인근에 위치하던 하센하이드 (Hasenheide) 공터에 투르넨이 이루어지는 장소인 투른플란츠 (TurnPlantz)를 처음으로 만들었다. 학생들을 위하는 마음이 컸던 로 맨틱한 교사 얀은, 모험을 좋아하는 학생들이 시도하던 놀이를 인위 적인 기구로 재현하여 교육에 활용하였다. 이 기구를 통해 학생들은 그들의 흥미와 열망을 체조로 승화할 수 있는 신체활동 체계를 접할 수 있었다(Guttmann, 1994).

점차 학생들은 이러한 얀의 열정과 배려를 이해하게 되고, 그의 교 육방식에 동화된다. 이 과정을 통해 체조는 널리 퍼지게 되었고, 그러 한 과정에서 얀이 추구하고자 했던 독일민족을 바탕으로 하는 강한 통일 독일 실현이라는 염원도 체조를 배우는 많은 이들의 염원으로 전이 되었다.

얀 체조를 가르치는 과정에서 학생들을 위한 슬로건이자 모토를 통 해, 체조에 참여하면서 자유주의적 민족주의자의 마음가짐을 가질 수 있도록 제시했다. 이는 fresh-pious-happy-free이다. 이러한 슬로건 을 통해 학생들의 생활방식을 설정하고 있다. 그는 체조에 참여하는 학생들이 활기차고, 부지런하며, 행복하고, 자유로운 삶을 영위할 수 있기를 바랐다(Hansen, 1997).

물론 얀의 체조교육은 강한 목적성을 띠고 있었기에 학생들에게 여 러 규칙과 의무를 부과하였다. 체조 교육 내에서 학생들은 신체를 통 제받거나, 규칙을 준수하도록 요구받았다. 예를 들어 학생들은 오와 
열을 맞추어 걷고 뛰는 활동을 통하여 규범과 절제를 받아들였다. 또 한 다양한 규칙이 있는 게임에 참여함으로써, 규칙과 질서를 따르고 이에 순응하도록 교육 받았다(Pfister, 2003).

하지만 이 부분은 학생들이 체조를 통해 신체적으로 건강하게 성 장하고, 정신적으로는 여러 규율을 내면화하여 도덕과 법률에 의거 한 삶을 살아가도록 지도하기 위한 것이었다. 이를 통해 민족의 번 영이라는 교육의 목적에 부합하는 학생으로 성장할 수 있도록 지도 하고자 한 것으로 보인다. 이러한 얀의 의도는 당시 독일의 학생들이 거칠고 무정부적이며, 폭력을 수반하는 여러 행동을 행하였으며, 낮 은 수준의 질서와 규율을 가지고 있었다는 점을 통해 짐작할 수 있다 (Krüger, 1996).

게다가 이러한 규칙과 질서는 체조에 참여하는 학생들은 그들의 사 회적, 경제적 지위에 상관없이 모두 자유롭고 평등하게 적용되었기 에 많은 학생들이 기꺼이 따랐다. 당시는 사회적 계층과 경제적 계 층이 분명하게 존재하던 시기였기에, 이러한 체조 교육은 학생들에 게 매력적이고 흥미있는 교육으로 다가갈 수 있었다(Kaimakamis, Kirialanis, Albanidis, 2008).

얀은 자신의 사상과 신념을 널리 퍼뜨리기 위해 제자이자 동료인 아이제렌(Ernst Eiselen)과 함께 학생들에게 가르치던 여러 가지 신체 활동을 총망라한 책인『Deutsche Turkunst(German art of turnen)』 을 출판하였다.

이 책에는 훈련법, 체조 용어, 체조 기구, 체조장의 건설 등 체조와 관련 있는 많은 것들이 포함되어 있었다. 그렇기에 체조를 실제로 접 하거나 배우지 못하더라도, 이 책을 통하여 체조를 배우고 훈련할 수 있도록 구성되었다. 이는 투르넨의 교과서이자 교리와 같은 역할을 하면서 많은 독일인들이 자발적으로 체조에 참여하도록 이끌었다.

하지만 얀의 체조가 아무런 어려움과 위기 없이 승승장구한 것은 아 니었다. 정부는 얀의 체조가 가진 이념적 배경은 그들의 이익과 반한 다고 여기고 있었다. 이는 얀의 체조에서 내세우는 가치가 자유주의적 민족주의에 해당하는 것이었기 때문이다. 얀은 자유와 평등, 국민들의 연대와 결속을 추구하는 사회를 이상적인 독일민족의 사회로 인식하 였지만, 당시 독일 내의 여러 정부는 전제군주국이자 군국주의적인 성 향을 강하게 띠고 있었기에 얀의 사상은 여러 정부에게 배척되거나 일 정 부분 반감을 살 수밖에 없는 상황이었다(Hansen, 1997).

그러던 중 독일과 러시아에서 활동하던 정치가이자 문학가인 코제 부(Augrust von Kotzebue)가 독일 청년에게 살해당하는 일이 일어 난다. 당시 코제부는 독일 내에서 이루어지는 자유주의적 민족주의 운동에 대해 신랄하게 비판하고 있었다. 그렇기에 많은 독일인은 그 가 독일의 민족주의적 움직임을 저해하고, 독일 사회를 혼란에 빠뜨 리려는 간첩일 것이라고 의심하고 있었다.

이에 1819년 3월 체조를 배우던 독일 청년 잔트(Karl Ludwig Sand)는 그를 살해하였다. 이를 계기로 얀의 체조를 부정적으로 바 라보던 당시 프로이센 정부는 체조를 금지하였다. 또한 학생들을 선동하고, 사회를 혼란스럽게 한다는 이유로 얀을 체포하게 된다 (Hansen, 1997).

하지만 체조가 금지된 이후에도, 독일의 청년들은 체조를 포기하지 않았다. 모든 주에서 체조가 금지된 것은 아니었고, 체조가 금지된 주 에서는 자신들의 집 마당과 집 안에 체조 기구들을 설치하고 이를 계 속하여 훈련하였다. 또한 체조에 열정을 갖던 독일인들은 ‘투르넨'이 라는 명칭을, 기존의 그리스 체조를 부르던 Gymnastic으로 대체하 기도 하였다. 이러한 명칭의 변경은 독일체조의 자주적 성격을 표현
하던 '투르넨'이라는 단어에 집착하기보다는, 실질적인 독일 내 체조 활동의 명맥을 이어가고자 하는 체조 지지자들의 의지를 분명하게 보 여주었다(Kaimakamis, Kirialanis, Albanidis, 2008).

한편 얀의 체조가 성장하는 과정에서 빠질 수 없는 인물은 얀의 제 자이자 동료였던 아이제렌(Eiselen)이다. 얀은 매력과 카리스마를 지 닌 인물로 묘사되는데, 아이제렌은 그의 자유주의적 민족주의 사상에 동화된 인물이었다(Eisenberg, 1996). 그는 얀이 투옥되어 있는 동안 체조를 지키고자 다양한 활동을 진행하고 이끌었다.

일례로 그는 체육과 스포츠를 지지하던 정부 관계자와의 끈질긴 협 상를 통해 개인적인 대규모 Fencing Hall을 건설할 수 있도록 허가받 았다. 그는 이곳에 펜싱 훈련을 명목으로 체조 기구를 설치하였다. 펜 싱 훈련의 일종으로 활용되던 체조 기구 훈련은 체조의 명맥이 이어질 수 있도록 도왔고, 이 펜싱 홀은 점차 체조를 위한 공간으로 활용된다.

그리고 아이제렌은 체조가 여성에게 활력을 줄 수 있다는 것을 이 해하고 있었다. 따라서 처음으로 여성을 위한 체조장을 건설하게 된 다. 이는 남성에게만 허락되어 있던 체조라는 신체문화를 여성들에게 개방함으로써, 금지정책으로 어려움을 겪던 상황에서 다시금 도약할 수 있는 계기를 마련해주었다. 그는 이러한 것 외에도 체조 기구들을 개량 및 전문화한다거나, Turnplantz의 사진을 책으로 출간함으로써 체조에 대한 대중적인 열망과 바람이 끊임없이 이어지도록 노력하였 다(Kaimakamis, Kirialanis, Albanidis, 2008).

한편 체조에 대한 금지가 길어지자, 많은 이들은 이에 저항하기 시 작하였다. 독일의 의사, 트레이너, 교육학자, 정치가 등은 체조의 필 요성과 우수성을 역설하며, 체조에 대한 금지를 철폐하고자 주장하였 다. 이러한 주장들은 1840 년에 받아들여지고, 정책적으로 이루어지 던 체조에 대한 금지는 사라지게 되었다(Kant, 2016).

이처럼 얀의 체조는 19 세기 전반부를 관통하는 거대한 민족주의 운 동이자 신체문화로서 사회에 지대한 영향을 주었다. 얀이 추구하였던 자유주의적 민족주의는 꽤나 널리 전파되었고, 수많은 독일인들을 감 화시켰다. 하지만 독일의 일부 계층에게만 향유되는 한계 역시 지니 고 있다(Krüger, 1996).

\section{‘국가주의적 민족주의'의 관점에서 본 스피스의 체조}

이번 절에서 필자들이 중점적으로 바라보는 스피스의 사상을 절의 서 두에 간략히 요약하면 이렇다. 그는 학교 내에서 체조를 교육하도록 하는 것에 중점을 두었고, 결국 체조교육의 학교 내 의무화를 이끈 인 물이다. 하지만 체조교육의 의무화를 이끌었다는 사실보다 우리가 주 목해야 하는 점은 그가 바라보는 학교의 목적이다.

그는 학교 교육의 목적을 군사교육의 목적과 동일한 것으로 바라보 았다. 즉 군대와 마찬가지로 학교에서는 국가를 위해 헌신할 수 있는 학생을 양성해야고 주장하였다. 필자들은 이 점을 주목하고 있고, 이 에 대해 아래에 조금 더 상세히 서술하고자 한다.

얀의 체조는 자유주의적 민족주의를 바탕으로 많은 이들을 감화시 켰으며, 체조가 독일민족 특유의 대중운동으로 자리 잡을 수 있도록 하였다. 그렇기에 얀은 학생 뿐만 아니라 일반시민들을 대상으로 투 르넨 운동을 전개하였다(Krüger, 1996). 하지만 19세기 독일체조의 또 다른 지도자였던 스피스는 학교 내에서 체육교육의 일환으로 체조 를 활용함으로써 국가주의적인 목적을 달성하고자 하는 것에 더욱 비 중을 두었다(Oh, 1989).

스피스는 교육의 근본적인 목적과 과제를 규율이나 질서를 내면화 
하는 것으로 보았다. 그리고 이러한 목적을 달성하기 위해 학생들에 게 규칙과 법의 통제에 복종하고 순응할 것을 요구하였다. 물론 얀의 체조 역시 학생들에게 의무와 규칙에 순응할 것을 요구하였다. 하지 만 근본적으로 얀과 스피스의 체조는 목적에서 차이가 나타난다. 얀 의 목적은 더 나은 시민들을 육성하고 이를 통해 강한 민족 국가를 만 들고자 한 것에 있었지만, 스피스가 이러한 복종을 요구한 이유는 국 가를 위해 헌신할 수 있는 시민과 유능한 군인을 육성하고자 함이었 다(Kant, 2016).

스피스가 체조를 받아들이고 심취하게 된 것은 그의 성장 배경과 관련 있다. 먼저 그는 유년기부터 체조교사였던 아버지의 영향을 크 게 받았다. 그의 아버지는 범애주의에 입각하여 학생들에게 체조를 가르치던 교사이자. 중상류층을 대상으로 하는 학교를 설립하여 운 영하던 학교 운영자였다. 자연스럽게 그는 아버지가 경영하던 학교에 입학하여 체육교육을 일찍이 경험하였다(Kwak, 2008).

비슷한 맥락으로 스피스는 열살 무렵 구츠무츠와 실제로 대면하 는 기회를 가지면서 체조에 깊은 관심을 갖게 되었고, 그의 삶에 얀의 체조가 스며들게 된다. 또한 스피스가 체조의 용어 및 훈련방법 등의 기초를 배우고, 그것에 대한 이해를 넓혀 나가는 데 큰 도움을 준 것 은 얀과 아이제렌의 저서였던 『Deutsche Turkunst(German art of turnen)』였다(Oh, 1989).

하지만 아이러니하게도 스피스는 얀의 체조와는 조금은 다른 자신 만의 사상의 길로 접어들게 된다. 얀의 저서는 애국심을 강조하면서 국가와 민족의 의미를 짚고 있었는데, 이 저서를 통해 스피스는 얀과 는 다른 국가주의적 민족주의에 대한 기초적인 사상을 정립한다. 또 한 그는 이 저서에서 청소년이 체조를 통해 많은 것들을 얻고 교육받 을 수 있음을 받아들일 수 있었다. 이러한 것들은 훗날 스피스가 체조 교육을 통해 이루고자 하는 국가주의적인 체조와 학교교육을 강조하 던 교육관의 토대로 자리잡는다(Kwak, 2008).

스피스가 자신만의 체조관을 정립하는 데 도움을 준 여러 교육자가 있었다. 그는 아버지의 영향을 받아 여러 명사들을 만날 수 있었는데, 그중 가장 널리 알려진 이는 유아교육의 아버지라고 불리우는 프뢰벨 (Friedrich Froebel)다. 그 역시 얀의 Trunen의 영향을 크게 받은 인 물이었기에, 스피스가 추구하는 체조활동에 적극적으로 협조하였고 지원을 아끼지 않았다.

스피스는 체조뿐만 아니라 학교 교육 전반을 포괄하는 여러 주제에 대해, 프뢰벨 및 그의 동료들과 의견을 나누고 서로의 경험을 공유할 수 있었다. 이러한 과정에서 스피스는 학교교육과정과 체육의 결합방 안, 학교 내 체육교육의 실시방안, 체육교재의 개선과 발전을 위한 방 법 등을 고민할 수 있었다. 그리고 이러한 고민을 바탕으로 『체조기술 론』을 완성하였다(Oh, 1989).

이 저작을 통해 스피스는 얀의 체조를 비판하고 자신의 체조를 만 들어갔다. 그는 얀과 아이제렌의 체조 방식에는 체계적인 이론이 부 재함을 지적하였다(Tröhler, 2017). 그렇기에 스피스는 체조의 동작 들을 세분화 및 체계화하였고, 이를 바탕으로 동작을 세세하게 분류 하였다. 이러한 분류는 동작 간의 위계를 형성하는 데 주효했고, 이는 체조 교사가 더욱 수월하고 효율적으로 체조를 가르칠 수 있도록 하 였다(Kwak, 2008).

이와 동시에 스피스는 체조가 제대로 된 이론적인 토대 위에서 제 대로 정립될 수 있도록 체조의 이론화 작업을 진행하였다. 이 과정에 서 그는 얀의 체조와 다른 몇 가지를 새롭게 강조한다.

우선 그는 맨손체조의 중요성을 강조한다. 그는 얀의 체조가 체조
용구를 빈번하게 활용하는 것은 신체의 일상적인 상태에서의 발달을 고려하지 않은 것이라 지적한다. 그리고 이 과정에서 개인이 체조 용 기구의 존재에 신체가 종속되는 상황을 야기할 수 있다고 경고한다 (Kant, 2016).

그렇기에 그는 신체를 전반적으로 발달시키기 위해서는 용구를 사 용하는 경우와 그렇지 않은 경우 모두를 포함하여 다양한 방법으로 신체를 단련해야 한다고 주장한다. 이러한 이유로 스피스는 지면 위 에서 기구 없이 할 수 있는 맨손체조를 체조활동의 기본으로 삼았다. 이를 위해 서기, 걷기, 도약, 달리기, 돌기 등의 여러 상태에서 할 수 있는 신체활동을 강조하여 지도하였다(Kwak, 2008).

스피스가 중시하던 또 다른 방식은 집단으로 하는 질서훈련이었다. 그는 이러한 훈련을 단지 많은 사람이 동시에 운동하는 단체운동으로 인식하지 않았다. 그는 집단 내의 개인들이 서로 상호 관계를 맺는 활 동의 하나로 인식하였다. 그리고 이는 개인이 집단 내에서 동시에, 같 은 공간에서 같은 활동을 함으로써 질서와 규율을 받아들이는 훈련이 기도 하였다. 이러한 활동의 목적은 외적으로 질서를 유지하고, 내적 으로는 규율에 순응하는 학생을 육성하기 위함이었다(Oh, 1989).

앞서 서술한 맨손운동과 집단으로 이루어지는 질서훈련의 강조는 스피스가 체조교육의 목적으로 하고 있는 바를 분명히 나타낸다. 그 는 학생들이 대규모로 동시에 같은 동작을 취하면서 가들 간의 일체 감을 형성하기를 바랐다. 또한 이러한 일체감은 국가와 민족의 번영 을 향해 있어야 한다고 보는 것이 타당하다.

또한 스피스는 여학생 또한 남학생과 마찬가지의 목적으로 체육교 육에 참여해야 한다는 의견을 가지고 있었다. 그렇기에 스피스는 남 학생과 같은 맨손체조와 질서운동을 여학생에게도 지도하였다. 스피 스가 여학생에게도 남학생과 같은 방식의 체육교육이 요구된다고 주 장하는 이유는, 학교교육의 목적이 개인의 건강증진이나 신체기능의 개선보다는 규율과 질서의 내재화에 있다고 보았기 때문이다. 따라서 성별에 따른 신체적인 능력의 차이는 스피스에게 크게 중요한 요소로 인식되지 않았다(Oh, 1989).

이러한 스피스의 사상은 「학교체육시행안」(1842)에서 이미 드러나 고 있다. 그는 학교교육과 군사교육의 결합을 주장하였고, 학교에서 의 규율은 군대 내에서의 기강과 본질적으로 같다고 보았다. 이러한 관점은 학교설립의 목적을 상비군 및 국토방위를 위한 예비군인을 양 성하는 것이라는 인식에서 출발하고 있다.

그렇기에 스피스는 학교 또한 군대처럼 하나의 생각과 행동을 공유 하는 집단이 되길 바랐고 이를 통해 학교와 군대가 합치된 목적을 갖 기를 바라고 있었다(Oh, 1989).

결과적으로 스피스는 학교, 군대, 국가가 일관된 목적과 시스템으 로 연결된 사회를 이상적으로 여기고 있었다. 그렇기에 개인의 능력 차이, 성별에 따른 신체적인 차이는 중요한 요소로 고려될 수 없었다. 또한 스피스의 사상에서는 개인이 주체적으로 설 수 있는 자리는 거 의 없는 것으로 보인다. 개인은 집단을 위해 집단의 사상과 규율을 받 아들이는 것이 미덕이며, 집단을 존재로서의 개인이 당연하게 인식되 는 그의 사상에서는 '국가주의적 민족주의'의 성격을 엿볼 수 있다.

\section{독일체조 민족주의의 변화 원인 분석}

이번 장에서는 얀의 사상과 궤를 같이하는 '자유주의적 민족주의'의 성격을 지녔던 독일체조가 스피스 '국가주의적 민족주의'의 성격으로 
변화한 이유에 대해 서술하고자 한다.

이 과정은 ‘우연'하게 이루어진 것이 아니다. 단지 우연히 얀이라는 자유주의적 민족주의자 의해 독일체조가 창안되었고, 또 한번의 우연 으로 스피스라는 국가주의적 민족주의자가 나타나 독일체조의 성격 을 변화시킨 것이 아니라는 것이다.

당시 독일체조가 지녔던 민족주의적인 성격의 변화는, 독일 사회가 마주하던 상황과 독일체조의 성격에 비추어 볼 때 일정 부분 자연스 러운 결과였다. 따라서 아래에서는 독일민족이 마주하던 상황과 독일 체조의 특징을 외적인 배경 요소와 내재적 한계로 구분하여 서술하고 자 한다.

이를 서술하기에 앞서, 당시 독일 사회가 마주하던 유럽의 전반의 민 족주의에 대한 이해가 선행될 필요가 있기에 간략하게 유럽의 민족주의 와 관련지어서, 외적인 배경 요소 및 내적인 한계를 이야기하고자 한다.

유럽은 국가(nation)을 탄생시키면서, 전근대적인 정치공동체의 소 멸과 근대적인 국민국가의 형성을 가장 먼저 이루어냈다. 이러한 국가 (nation)을 바탕으로 경제적으로는 자본주의가 성장하게 되었고, 정 치적으로는 잠시 절대왕정을 거치지만 결과적으로는 개인이 주권을 갖는 국민주권과 민주주의를 성공적으로 안착시킨다(Hong, 2019).

이러한 과정에서 개인은 그들의 권리를 강조하고 확장하면서 근대 적인 국민국가의 틀 내에서 민주주의를 지향하는 정치적인 공동체를 내부적으로 발전시켜왔다. 이러한 서술에 해당하는 사례로 인정되는 것들이 영국이나 미국의 애국주의(patriotism)나 프랑스의 공화주의 (republicanism)이다(Kwon, 2020). 그리고 이러한 국가들의 내부에 서는 개인의 자연권이 존중되면서 민주적으로 성숙한 형태의 민주주 의 사회가 아래로부터의 힘에 의해 탄생할 수 있었다.

하지만 유럽의 모든 국가가 이러한 시나리오대로 국민국가를 탄생 시킨 것은 아니다. 독일, 이탈리아, 러시아 등의 이른바 후발 국가에 서는 이와 상반된 형태의 사회가 출현한다(Giddens, 1987). 상대적 으로 국민국가의 출범이 늦은 후발 국가들은 국민 개개인의 자연권을 보장하고, 이를 통한 성숙한 개인들이 만들어내는 민주적인 사회로의 진입 단계에 다다르지 못하였다. 후발 국가에게는 민주적으로 성숙한 개인들에게서 나오는 아래로부터의 힘을 기다릴 시간이 없었다.

아마도 이 과정을 기다리기에는 뒤쳐지는 국가로서 느끼는 열패감 이나 조바심이 컸기 때문일 것이다. 결과적으로 이러한 국가들은 아 래로부터의 힘이 아닌, 위로부터의 국가주의적 움직임이 사회를 움직 이는 원동력으로 작용하게 되었다(Giddens, 1987).

앞서 서술한 것처럼 독일은 이러한 후발주자의 대표 격에 해당하는 국가였다. 즉 유럽 내에서 독일이 갖는 위치는 자유주의적 민족주의가 성공하기 어려운 '외적인 배경요소'를 포함하는 사회일 수밖에 없었다.

따라서 독일 사회는 국민 개개인이 정치 사회적인 주체로서 인정되 는 사회라기보다는, 국가나 민족이라는 집단적 주체의 일부로서 인식 되는 사회로 나아간다. 그리고 이러한 집단적인 주체의 강조는 개인 의 사회적 주체로서의 발달을 가로막는 요소로 작용하게 되었다.

그렇기에 얀이 강조하던 '자유주의적 민족주의'가 독일 사회에서 성공하는 것은 후발주자라는 태생적인 한계를 극복하지 않고서는 어 려울 수밖에 없었다. 그렇기에 개인이 사회의 주체로 성장하고, 성장 한 개인이 민주적인 정치 체제를 이루어내며, 아래로부터의 힘에 의 한 통일 독일을 이루어내고자 했던 얀의 바람은 애초에 성공하기 힘 든 시도였다고 볼 수 있다.

한편 독일체조는 ‘내재적 한계’도 함께 지니고 있었다. 독일 체조는 이른바 신체문화로서 '민족(folk)' 공동체를 중심으로 하는 민족주의
운동이었다. 이렇게 문화를 중심으로 하는 민족공동체 중심의 민족주 의 운동은 앞서 II장에서 서술하였듯이 주관적인 기준으로 적용되기 어려웠다.

하지만 이러한 어려움은 앞서 언급한 추상적인 수준에서 그치는 것 이 아니었다. 민족공동체가 국가(nation)의 수준으로 나아가기 위해 서 선결되어야 할 영토의 문제와 국민의 문제로 귀결되는 굉장히 중 요한 부분이었다. 즉 '어디까지가 독일의 영토인가', '독일 국민이 될 수 있는 범위는 어디까지인가'라는 현실적인 문제에 봉착하게 된다.

예컨대 독일의 체조 문화를 향유하는 지역을 모두 독일의 영토로 한다는 것은 애초에 불가능한 이야기이다. 또한 현실적으로 누구든지 체조를 배울 수 있는 환경이었던 독일 사회 내에서, 체조를 익힌 이들 을 독일 국민으로 인정한다는 것 역시 어불성설이었다. 따라서 독일 체조라는 민족주의 운동을 기준으로 국가(nation)를 규정하는 것은 어려웠다.

이는 비단 체조의 문제가 아니었다. 주로 시를 다루었던 문학가이 자 민족주의의 선구적인 인물인 헤르더(Johann Herder) 역시, 민족 이 국가를 갖는 것은 자연스러운 것이라고 강조하였다. 하지만 실질 적으로 여러 나라와 민족이 뒤섞여 살고 있었던 당시 독일의 특성상, 문화는 결코 현실의 국가로 이어질 수 없는 상상의 무언가일 수밖에 없었다(lepsius, Campbell, 2004). 즉 문화를 바탕으로 하는 민족공 동체를 국경과 법, 제도에 의해 귀속되는 '국가'로 전환하고자 하는 시 도 자체가 무모한 도전이었다고 볼 수 있다.

자유주의적 민족주의의 입장에서는 프로이센의 군대에 의해 독일 이 통일이 된 이후 상황은 더욱 악화되었다고 볼 수 있다. 독일체조라 는 문화적인 운동이 국가공동체와 대립하면서 '자유주의적인 민족주 의'운동으로서의 성격을 유지하는 것은 독일인들에게 인정받기 어려 웠다. 심지어 체조 문화를 받아들이고 배우는 체조인들에게도 국가 (state)공동체가 통일 독일 국가(nation)으로 전환되는 것이 상대적으 로 자연스럽게 받아들여지게 되었다. 그렇기에 문화의 범주에 속하는 독일체조는 내재적인 한계를 지니고 있었고, 이에 '자유주의적 민족 주의'의 성격은 변화될 수밖에 없었다.

이 외에도 체조 지도자의 잘못된 판단에 의해 얀의 체조가 전반적 으로 쇠퇴하는 모습이 나타나기도 한다. 얀의 제자이자 투르넨의 새 로운 지도자였던 마스만(Massmann)은 체조 초기의 모습을 이상적으 로 생각하였다. 하지만 이는 많은 독일인들이 체조에 열정적으로 참 여하였던 19세기 초 독일체조의 향수에서 비롯하는 잘못된 판단이었 던 것으로 보인다.

그는 체조 지도자로서 전국적인 체조교육 실시방안을 모색하기 위 해 베를린으로 초빙되었다. 이 중요한 자리에서 마스만은 그가 평소 이상적인 모습으로 꿈꾸던 독일체조의 초창기 형태인 대운동장을 설 치할 것을 주장하였다. 구체적으로 보자면 그는 도시별로 하나의 중 앙 대운동장을 설립하고, 남녀노소를 불문한 각 계층의 사람들이 모 여서 체조를 하는 것이 체조의 부흥이 효과적이라고 생각했다. 이를 위해 체조를 거대한 공설운동장에서 자유롭게 체육활동을 진행하는 대중운동으로서 규정하고자 했다.

하지만 이는 체조의 체계화라기보다는 대강화를 야기하는 결과를 가져왔다. 또한 체계성을 갖춘 학교의 체육교육으로 체조를 활용하고 자 했던 당국의 의도와도 동떨어진 적합하지 않은 방법이었다. 이 과 정을 거치면서 체조 운동장에 나오는 사람들의 수는 기존의 반 정도 까지 줄어들게 되었다.

심지어 마스만의 지도 시기에 체조계의 대부 역할을 하던 아이제렌 
이 사망하면서 체조교사의 양성과정에도 문제가 생기게 된다. 이러한 일련의 일들에 의해 마스만은 점차 지도자로서 신뢰를 잃고 1850 년 퇴임하게 되었다(Oh, 1989).

이러한 마스만의 패착은 얀의 체조가 자신의 색을 잃고 스피스의 체조로 넘어가는 계기를 마련한 것으로 보인다. 따라서 이 경우도 얀 의 '자유주의적 민족주의'체조가 스피스의 '국가주의적 민족주의' 체 조로 변화하게 된 일련의 원인 중 하나로 볼 수 있다.

이렇게 독일체조는 독일 사회의 자유주의적 민족주의가 마주하는 한계를 그대로 재현하기도 하고, 역사적으로 중요한 역할을 맡았던 지도자의 패착으로 인해 인기를 잃기도 하면서, 민족주의적인 성격의 변화를 경험하게 된다. 독일체조의 사례는, 어찌 보면 독일 사회 전반 에 흘렀던 분위기를 거스를 수 없었던 하나의 신체문화로서 당연하게 보일 수 있다.

하지만 수많은 독일인들이 참여하였고, 자유와 평등, 민주주의를 실현하고자 했던 열망을 내재했던 독일체조가 변화했다는 사실에 우 리는 한번 더 주목할 필요가 있다.

\section{결론 및 제언}

지금까지 19세기 독일체조의 민족주의적 성격이 변화하는 모습과 그 이유에 대한 '정보'를 제공하고자 하였다. 당시 독일 사회는 혼란스러 웠지만 다양했던 진보적 열망을 내포하고 있었다. 또한 개인이 사회 의 주체로 성장하여 국가를 움직이는 아래로부터의 힘을 가진 사회 로 나아갈 가능성을 품고 있었다. 하지만 여러 이유들로 인해 독일 사 회는 그러한 진보적인 동력을 상실하고, 국가주의적인 경직된 사회로 접어들게 된다.

이러한 과정은 독일체조의 변화에도 그대로 재현된다. 19세기 초 자유주의적 민족주의자인 얀의 사상을 토대로 했던 독일체조는, 19세 기 중반 이후로 접어들면서 국가주의적 민족주의자인 스피스의 영향 을 받아 점차 국가주의적인 신체문화로 변해가게 되었다. 이 변화는 독일체조의 외부적인 배경 요소와 내재적 한계 등으로 인해 필연적으 로 이루어질 수밖에 없었던 것으로 보인다.

이 연구에서 독일체조 민족주의의 변화를 짚은 것처럼, 모든 역사에 대해 우리는 원인을 분석할 수 있다. 하지만 이러한 행위들은 역사라는 학문적 특성상 결과론적인 형태를 띨 수밖에 없다. 그렇다고 하더라도 이러한 역사 연구에 대한 가치는 결코 평가절하되어서는 안 된다.

그리고 이 연구처럼 당장은 주목받지 못하고 있지만, 살펴볼 만한 역사적인 사례들이 더 발굴할 필요가 있을 것이다. 이러한 연구를 통 해 우리에게 과거를 제시함으로써 현재에 대한 경각심이나 시사점을 제공해 줄 수 있다면, 이는 역사학을 공부하는 사람이라면 가장 바라 마지 않는 모습일 것이다.

끝으로 역사에 만약은 존재하지 않지만, 만약 독일체조로 인해 독 일 사회가 '자유주의적인 민족주의로 잘 성장하였더라면 어떠했을까' 라는 상상을 하게 된다.

물론 지금은 선진국의 표본으로 많은 이들에게 여겨질 만큼 달라졌 지만, 근현대의 독일은 독일문제(German problem)라는 표현이 생 겨날 정도로 큰 문제적 국가였다. 그리고 이러한 문제의 근본에는 '국 가주의적 민족주의'가 내재하고 있었다. 이러한 사실에 주목하며 작 금의 우리 사회 역시 집단적 주체가 지나치게 발현되는 부분이 없는 지, 고민해볼 필요가 있지 않을까 하는 마음으로 글을 마무리한다. 


\section{참고문헌}

Breuilly, J. (1990). Nation and nationalism in modern German history. The Historical Journal, 33(3), 659-675.

Breuilly, J. (1992). The state of Germany: the national idea in the making, unmaking and remaking of a nation-state. London: Longman.

Cazers, G., \& Miller, G. A. (2000). The German contribution to American physical education: A historical perspective. Journal of Physical Education, Recreation \& Dance, 71(6), 44-48.

Eisenberg, C. (1996). Charismatic nationalist leader: Turnvater Jahn. The International Journal of the History of Sport, 13(1), 14-27.

Elias, N. (1978). The Civilizing Process: The History of Manners. Oxford: Basil Blackwell.

Gerber, E. W., \& Redmond, G. (1971). Innovators and institutions in physical education. Sport History Review, 2(2), 81-83.

Giddens, A. (1987). Social theory and modern sociology. Stanford: Stanford University Press.

Guttmann, A. (1994). Games and empires: modern sports and cultural imperialism. New York: Columbia University Press.

Guttmann, A. (2004). From ritual to record: The nature of modern sports. New York: Columbia University Press.

Hansen, J. (1997). Politics and gymnastics in a frontier area post-1848. The International Journal of the History of Sport, 14(3), 25-46.

Hofmann, A. R. (2004). Turnen and sport. New York: Waxmann Verlag.

Hong, T. Y. (2019). From nationalist nationalism to liberal nationalism? Or across national boundaries?. Philosophy and Reality, 95-108.

Jansen, C. (2011). The formation of German nationalism. The Oxford Handbook of Modern German History, 234.

Jia, M. I. A. O. (2011). Discussion on the contribution to school sport development of GutsMuths. Journal of Sports and Science, 6.

Kaimakamis, A., Kirialanis, P., \& Albanidis, E. (2008). Gymnastics and the ideological movement of Friedrich Ludwig Jahn. Studies in Physical Culture \& Tourism, 15(1), 43-47.

Kaimakamis, V., Dallas, G., Stefanidis, P., \& Papadopoulos, G. (2011). The spread of gymnastics in Europe and America by Pedagogue-Gymnasts during the first half of the 19th century. Science of Gymnastics Journal, 3(1), 49.

Kang, C. G. (2001). The historical development of German nationalism and its future. Ewha Historical Institutions, 28, 133-150.

Kant, M. (2016). German gymnastics, modern German dance, and Nazi aesthetics. Dance research journal, 48(2), 4-25.

Kim, B. C. \& Seo, J. C. (2012). Douglas Booth`s critical perspectives on modern sport historiography and its implications for Korean sport historiography. Korean Journal of Physical Education, $51(5), 1-15$.

Kim, C. N. (2002). Nationalism and national literature of Germany. Studies in Foreign Literature, (11), 5-154.

Kim, M. S. (2009). Social functions of women's gymnastics and sport in modern Germany. Journal of Korean Physical Education
Association for Girls and Women, 23(1), 27-38.

Kretchmar, R. S., Dyreson, M., Liewellyn, M., \& Gleaves, J. (2018). History and philosophy of sport and physical activity. IL: Human Kinetics.

Krüger, M. (1996). Body culture and nation building: the history of gymnastics in Germany in the period of its foundation as a nationstate. The International Journal of the History of Sport, 13(3), 409-417.

Krüger, M. (2015). Global perspectives on sports and movement cultures: From past to present-Modern sports between nationalism, internationalism, and cultural imperialism. The International Journal of the History of Sport, 32(4), 518-534.

Krüger, M. (2018). Gymnastics, physical education, sport, and christianity in Germany. The International Journal of the History of Sport, 35(1), 9-26.

Krüger, M., \& R. Hofmann, A. (2015). The development of physicaleducation institutions in Europe: a short introduction. The International Journal of the History of Sport, 32(6), 737-739.

Kwak. J. H (2008). Adolf Spiess's Education Aspect of Physical Education in school(Masters dissertation). Kyungpook National University, Daegu, Korea.

Kwon, J. K. (2020). The reality of globalization and the future of nationalism: Searching for alternatives. Society in Philosophy East-West, (96), 371-400.

Lee, D. K, \& Jeong, J. W. (2000). A study on developmental Pmoees of Jahn's gymnastics. Korean Journal of History of Physical Education, Sport and Dance, 5(1), 48-56.

Lepsius, M. R., \& Campbell, J. A. (2004). The nation and nationalism in Germany. Social Research, 71(3), 481-500.

Mechikoff, R. A. (2006). A history and philosophy of sport and physical education: From ancient civilizations to the modern world. Boston: McGraw-Hill.

Merkel, U. (2003). The politics of physical culture and German nationalism: Turnen versus English sports and French olympism, 1871-1914. German Politics \& Society, 21(2), 69-96.

Nam, S. C., Soh, H., \& Kim, D. W. (2017). A study on the introduction and establishment process of western modern gymnastics. The Korean Society of Sports Science, 26(5), 1-10.

Naul, R. (2002). History of sport and physical education in Germany, 1800-1945. Sport and Physical Education in Germany(pp. 1527). London; New York: Routledge.

Naul, R. \& K. Hardman (Ed.). (2002). Sport and physical education in Germany. London; New York: Routledge.

Oh, D. S. (1989). The Thoughts of Adolp Spiess and the Physical Education in Prussian Schools. Kyungpook National University Sport Science Research, 5(1), 19-37.

Oh, D. S. (2006). The change of German gymnastic systems and physical education ideas in modern Germany. Korean Journal of History of Physical Education, Sport and Dance, 18(1), 167-181.

Park, S. W. (2017). From Turnen to soccer. History \& the Boundaries, (102), 273-305. 
Pfister, G. (2003). Cultural confrontations: German Turnen, Swedish gymnastics and English sport-European diversity in physical activities from a historical perspective. Culture, Sport, Society, 6(1), 61-91.

Pfister, G. (2009). Epilogue: gymnastics from Europe to America. The International Journal of the History of Sport, 26(13), 2052-2058.

Pfister, G. (2009). The role of German turners in American physical education. The International Journal of the History of Sport, 26(13), 1893-1925.

Reicher, D. (2020). Nationalistic German gymnastic movements and modern Sports. Culture Between Identity and Habitus. Historical Social Research/Historische Sozialforschung, 45(1), 207-225.

Schulze, H. (1991). The course of German nationalism: From Frederick the Great to Bismarck, 1763-1867. Cambridge: Cambridge University Press.

Sheehan, J. J., \& Sheehan, J. J. (1993). German history, 1770-1866. New York: Oxford University Press.

Tröhler, D. (2017). Shaping the national body: Physical education and the transformation of German nationalism in the long nineteenth century. Nordic Journal of Educational History, 4(2), 31-45.

Yildiz, M., \& Devecioglu, S. (2013). Currents of physical education in Europe in the 18th and 19th centuries and in German and Swedish gymnastics. The Annals of "Dunarea de Jos" University of Galati. Fascicle XV, Physical Education and Sport Management, 2, 176-178.

Živanović, N., \& Milošević, Z. (2017). Organised Physical exercising of the 19th Century: The need, politics, ideology. Physical Education and Sport Through the Centuries, 4(2), 15-29. 


\title{
19세기 독일체조 민족주의의 변화에 관한 논의: 두 명의 민족주의자를 중심으로
}

\author{
정동수 ${ }^{1}$, 김방출 ${ }^{2}$ \\ ${ }^{1}$ 서울교육대학교 박사과정 \\ 2 서울교육대학교
}

[목적] 본 연구는 19세기 독일체조의 민족주의 변화의 과정과 원인을 파악하는 것을 목적으로 한다.

[방법] 연구방법은 문헌연구법으로 기존의 연구를 통해서 이미 축적되어있는 데이터를 분석하였다. 자료수집 방법과 관 련하여, 국내 연구자료는 RISS에서 ‘독일체조', '투르넨', '독일 민족주의'로 검색하여 연구 주제와 관련있는 11 편을 활용 하였다. 해외 연구자료는 구글스칼라에서 'German gymnastics', 'Turnen'을 검색하여 나오는 연구 중 본 연구와 관련 있는 7편을 중심으로 이루어졌다.

[결과] 첫째, 독일의 민족주의는 자유주의적 민족주의와 국가주의적 민족주의로 분화하였다가, 독일의 통일 이후 국가주 의적 민족주의로 귀결되었다. 둘째, 얀은 자유주의적 민족주의자로서, 스피스는 국가주의적 민족주의자로서, 독일체조를 통해 자신의 사상을 전파하고자 하였다. 셋째, 독일체조는 얀의 자유주의적 민족주의에서 스피스의 국가주의적 민족주의 로 변화하였는데, 이는 독일체조의 외부적 배경과 내재된 한계에 의해 필연적으로 이루어질 수밖에 없었다.

[결론] 본 연구에서는 19 세기 독일체조의 민족주의적 성격이 변화하는 과정과 원인을 보여주었다. 그리고 아직 주목받지 못하였지만 알아볼 가치가 있는 역사적 사례들이 다양하게 연구될 필요가 있음을 제언한다.

주요어

민족주의, 민족주의자, 독일체조, 프리드리히 얀, 아돌프 스피스 